\title{
A Study on the Digitalized Human Resources (HR) Practices in Digitalized Business Era in India
}

\section{OPEN ACCESS}

Manuscript ID:

MGT-2021-08033560

Volume: 8

Issue: 3

Month: January

Year: 2021

P-ISSN: 2321-4643

E-ISSN: 2581-9402

Received: 12.10 .2020

Accepted: 25.11 .2020

Published: 01.01.2021

Citation:

Shivaraj, G. "A Study on the

Digitalized Human Resources (HR) Practices in Digitalized Business Era in India."

Shanlax International Journal of Management, vol. 8, no. 3, 2021, pp. 83-89.

DOI:

https://doi.org/10.34293/

management.v8i3.3560

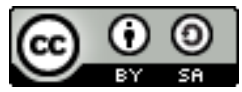

This work is licensed under a Creative Commons Attribution-ShareAlike 4.0 International License.

\author{
G. Shivaraj \\ Research Scholar, Department of Management Studies \\ Madurai Kamaraj University, Madurai, Tamil Nadu, India
}

\begin{abstract}
In organizations across the world, speed of advanced change is affecting issues connected with labour force enhancement, ability change, up-skilling and re-skilling, preparing, and resource development. These worries lie at the core of Human Resource Management (HRM) and require an adjustment in the customary working of HR groups. HRM in the advanced time defies difficulties on two fronts one, making organization measures computerized and information driven and two, changing the labour force and ways work is done in the organization. In straightforward speak, $H R$ works today cover a wide dispatch from system plan to accomplish a dexterous labour force to representative engagement and health rehearses. Beforehand, HRM was restricted to utility and paper serious capacities, for example, recruitment, preparing, and finance organization. Digitalization in HRM is the utilization of advanced innovation for the everyday implementation of an assortment of HR measures from recruitment to authority management. HR managers should reshape their usefulness and make the ideal advanced methodology to upgrade the representative organization relationship. The initial step is to define a reasonable ultimate objective that is, the thing that the key inspirations are moulding the digitalization technique. Truth be told, the robotization of useless cycles can standardize shortcomings and destabilize the organization. This is the reason distinguishing key organization factors while planning the digitalization procedure ought to be a first concern for HR managers. Organizations in most Indian businesses currently utilize organized information and innovation for dynamic and worker assessments dependent on ongoing input, intra-authoritative changes, and outside pressing factors. This is especially significant in a consistently changing and serious environment as is India's. Hence, the current study has been framed with the purpose to give an outline on the digitalized HR practices in digitalized business era in India and study is descriptive secondary data based one.
\end{abstract}

Keyword: Digital technology, Digital strategy, Recruitment to leadership management, Structured data, Real-time feedback, Competitive environment, Employee assessments

\section{Introduction}

In $21^{\text {st }}$ century, the world has gone through many changes dependent on strength of IT (Information Tool) instruments and advanced media. Digitalization is available all through each business and regular daily existences. It is an arising way to deal with strategic policies and worker's conduct. The digitalization is quickly developing a direct result of the dynamic conduct of the market. The organizations need to adjust these advancements for the better correspondence among workers and to acquire the upper hand. Advanced innovation assumes an essential job in Human Resource Management (HRM) and impacts its working in many ways. Aside from Human Resource Management System (HRIS), it likewise influences the other HR Practices. The HR practice of Human Resource Management (HRM) is worried about all parts of how individuals are utilized and managed in organizations. It covers exercises, for example, key HRM, Human capital management, information management, authoritative development, resourcing (Human Resource Planning, Recruitment and Selection and Talent Management) and performance management, learning \& development. 
Computerized innovation encourages the in the business. Past examination additionally organization to expand its profitability by amplifying its most significant resourcees 'Human'. Computerized HRM is a path by which procedures, strategies and practices can be adequately implemented. "An umbrella term covering all conceivable mix components and substance between HRM and IT targeting and making an incentive inside and across organization is for focused workers and management". The majority of the assignments related with HR are outsourced. Therefore, business requires all the more new mastery from their HR group.

Organizations in India are relied upon to grasp more intelligent advances and digitisation incredibly to change their human resources (HR) rehearses. Firms, particularly the new businesses, have just begun utilizing Artificial Intelligence (AI) and Machine Learning (ML) calculations to take care of complex issues in selecting. For example, HR capacities are progressively figuring out how to use large information investigation to mine the rich information that they have available to them today. This thusly helps the HR groups reveal shrouded examples, connections and other information driven bits of knowledge and therefore follow up on them. So, it is being a mandatory factor for the researcher to do theoretical study on current title.

\section{Research Objectives}

The present study associated with following primary and secondary objectives:

1. To know about the Human Resource Management in the Digitalized era.

2. To study the digitalized HR practices.

3. To concise the digitalization in various Human Resource (HR) practice dimensions

\section{Reviews of Related Literature}

Tripathi et al., (2017) have done an investigation and the point of this paper was to analyze the part of innovation and development rehearses in computerized period. These days, there is a lot of rivalry where imaginative human resource (HR) rehearses have become the requirement of great importance. There is a need to persistently create and enhance human resource practices to stay serious demonstrates that the result of creative HRM practices can be significant towards holding workers and their performance. As of now, every business should try to improve the nature of its labour force. To get the best human resource, a productive and all around arranged technique is needed at the working environment. Consequently, specialized advances are being made in the field of human resource with time and gradually the customary HRM is being supplanted by new and in fact progressed HRM. Further, research articles, reasonable investigations, audit papers and other important substance on the subject were gotten to and inspected through web sources and information bases, for example, Proquest, EBSCO host and Google researcher to accomplish the goal of the examination. In any case, this investigation adds to the current writing by explaining the part of inventive practices and innovation with regards to serious advanced environment.

Mruthyanjaya Rao, Mangipudi. (2018) have proposed an exploration paper to examine the arising patterns of human resource management regarding digitalization in HRM. The paper will talk about the development of digitalization in HRM throughout some stretch of time and its contemporary application in the execution of HRM procedures and arrangements. One of the preeminent territories the HR should center upon is "execution". The issue statement rotates around "execution", however the organization has a strong vision, phenomenal technique and right ability. The main concern for $\mathrm{HR}$ is to interpret this methodology and vision into execution and make it an enormous achievement. It is appropriate to guarantee the labour force in an organization is adjusted to its technique and need. Particularly, developing organizations don't have the advantage of having elite individuals relegated to do restrictive positions. It is in every case all hands on deck situation constantly. It is shrewd to take note of that the organizations are made a decision about not just on their monetary wellbeing, nature of service or labour force fulfillment yet in addition on how viably they coordinate with the outside world, clients, accomplices, and society on the loose. For this, the HR Managers have received the better 
approaches for releasing their capacities utilizing develop techniques and instruments like Cloud HR innovation, Artificial Intelligent driven devices, Adjusting the current working models, Adding vital incentive to the organizations, Automation of crucial HR capacities, for example, a) ability procurement, ability assessment, c) on-boarding, d) performance management, e) remuneration and advantages, f) augmenting the economies of scale, which means executing it better, quicker and less expensive.

Baykal, Elif. (2020) have summed up their investigation as late many years achieved astounding innovations that influenced organizations severally. With the most recent developments, organizations procured the capacities to complete their capacities all the more productively and quickly. Having a few undertakings influencing both inside and outside clients, human resources departments likewise profited by these mechanical developments. Inferable from the computerized insurgency, e-HR arose as another method of rehearsing HRM exercises with the most recent electronic and PC based devices and applications. These applications facilitated crafted by HR experts and served them the occasion to zero in on their center work, specifically vital human resources exercises instead of procedural desk work of the department. With a comprehensive and integrative methodology, this advanced change in HRM has been scattered among all services in human resources including recruitment, vocation management, preparing and development, performance management, and remuneration.

\section{HRM in Digitalized Era}

Nowadays, the digitization is changing the conventional style plan of action. Among all capacities Human Resources Management (HRM) is generally influenced by the digitization in view of expanding use of representative related programming, IT empowered HR capacities, Social organizations, and portable arrangements. The organizations are imbuing advanced methodology in dealing with their Human Resources (HR). There is a need to relentlessly create and to improve the human resource practices to stay serious in the business. What's more, the new investigations have indicated the organizations are planning carefully empowered representative driven HR rehearses. To convey the best outcomes and face the serious market the upgradation of HR is inescapable. In this manner, specialized advances are being made in the field of human resource with time and steadily the standard HRM is being supplanted by new and in fact progressed HRM.

From the development of new plan of action advancements to serious and customized representative projects, social impression of an organization and mechanical developments, the Human Resources industry is going through huge changes. There are colossal changes seen in the Human Resources industry today:

1. First, there is a development of new plan of action advancements which implies a move from the customary manager representative relationship towards a more different labour force biological system (for instance, an expansion in contract based workers, consultants and gig laborers).

2. Second, there is an expanding center around upper hand through remuneration programs, performance combination, personalization of advantages and investment on prosperity programs. In basic words, a motivating force program that offers to a 22-year-old may not display a similar impact on a 35 -year-old and consequently an organization's prize program needs to oblige various socioeconomics.

3. Third, arising ages is testing the customary profession ways with a rising demand on close to home interests, creating through cross-useful encounters and ceaseless re-skilling. Regularly you see representatives getting across capacities from human resources to back to advertising gradually and consistently fabricating their experience horizontally prior to taking the large jump vertically. So, there is an accentuation on ceaseless re-skilling.

4. Fourth, the financial changes where investment organizations screen the impression of an organization's system by the general public and rising assumptions on corporate social duty. Moreover, competitors like to join organizations known for their solid social program.

5. Lastly, mechanical advancements empower the utilization of man-made brainpower, mechanical 
technology, information mix, investigation and incorporation stages and subsequently the specialized establishment and level of information combination turns into a key for an information driven organization.

\section{Digitalized HR Practices}

In present situation, there appears to be the control of innovation everywhere on the world. Digitalization is an instrument which speeds up the correspondence cycle by decreasing the cost which encourages the organizations to be more gainful and to work all the more viably and effectively. The mechanical advancement helps in bringing new openings and strategies for working in an organization. The HR experts utilize these developments in a positive manner by changing methodologies in an advanced manner for the childhood of the organizations. Digitalization likewise helps in improving the aptitudes of the representatives like dealing with programming's and PC abilities. IT (Information Technology) has partitioned the advantages into three classes:

1. Transactional frameworks that cut expenses by subbing work and robotizing measures

2. Informational frameworks that cut expenses and improve efficiency by giving the data spine of a firm

3. Strategic frameworks that expansion creativity by empowering new items, services or the section into new market

From the above frameworks obviously computerized devices help the organizations in expanding efficiency, improving nature of work, expanding work environment wellbeing, decreasing expense and worker engagement.

\section{Digitalization in Various Human Resource (HR) Practice Dimensions}

E-HRM alludes to an incorporated, organization wide electronic organization of $\mathrm{HR}$ information, data, services, instruments, applications and exchanges. The utilization of any innovation empowering managers and representatives to have direct admittance to HR and other work environment services for correspondence, performance, detailing, group management, information management and learning notwithstanding regulatory applications. The entire capacities into two territories one is Process innovation and other is Human Capital Technology.

Process Technology offers help for fundamental exchanges. These capacities incorporate managing finance, individual/authoritative information and routine organization and are pointed toward lessening costs and accomplishing HR operational efficiencies through mechanization.

Human Capital Technology pointed toward supporting individuals management exercises, for example, performance management, abilities profiling and investigation. These capacities are all the more deliberately situated because of the more extensive effect on business result.

The effect of $\mathrm{Hr}$ innovation is probably going to be a mix of cycle and human capital. E-HRM innovation is progressing quicker as many organizations are dealing with web advances like e-recruitment by the gateways or sites, performance management programming's and e-learning for their labour force.

\section{Digitalization in Recruitment}

The recruitment business is the most seasoned industry among the other help enterprises of the world. Innovation positively affects recruitment. Recruitment is the way toward pulling in possible contender for the authoritative foreseen opening. E-Recruitment gives many advanced instruments. It has following sorts:

1. Operational E-Recruitment - this incorporates fundamental exchanges described by momentary candidate connections worldwide messages and significant robotization.

2. Relational E-Recruitment - this is portrayed by development of genuine candidate connections through better input, the personalization of candidate messages and the utilization of web 2.0 instruments, for example, informal community destinations.

3. Transformational E-Recruitment - it is secured in a worldwide ability management system, comprising in distinguishing the basic positions, and afterward pulling in and holding people who relate to the set up profile. 
Employer marking and notoriety could be a strong help. E-strategies Used in Recruitment are:

a. Company's sites are their own sites having a connection for professions alternatives where competitor can sign in with current openings or present the resume for better chances. Many organizations utilize this technique for recruitment like thought, $\mathrm{HCL}$, Wipro and so on these organizations have separate selection representatives group for reacting towards these exercises.

b. Commercial Job entryways are the sites that permit representatives to post their work requirement for the satisfying of their opening and competitor post their resume for landing the position openings. The places of work in India are Naukri.com, Monster.com, Times work, shine.com and so forth.

\section{Digitalization in Training Development}

IT instruments have influenced the method of formal learning in a work place. In the time of digitalization, E-Learning gives a colossal occasion to the representatives by making learning additionally fascinating and appealing. "E Learning alludes to the utilization of web advances to convey an expansive method of arrangements that upgrade information and performance". The preparation changes from fundamental preparing exercises like talks, contextual analyses, pretend and so forth to the more mind boggling procedures like innovation based learning, video, web and PC based. Many public just as private area organizations are receiving the idea of E-Learning. E-Learning alludes to discovering that relies upon or is improved by electronic or online correspondence utilizing the most recent data and correspondence innovation.

\section{Digitalization in Performance Management}

Performance estimates the worker productivity and viability in the achievement of authoritative objectives. E-Performance Management is the arranging and implementation of Information innovation in managing PM System. E-PM is the piece of E-HRM. IT empowered PM goes to a successful instrument to use the full advantages of the framework at a similarly lesser expense of organization. The E-PM permits the organizations to keep up the record of center aptitudes and skills into the worker's managing cycle. With the rise of innovation, performance evaluation programming's are getting normal in the organizations.

Performance management programming causes the HR to carryout performance of the worker in the best manner, by saving time and cost. Performance management programming gives a creative way to deal with workers performance evaluations. It gives performance audit as well as aided in expanding efficiency, relationship, conduct, development and center competency.

\section{Digitalization in Payroll Management}

Finance is characterized as a strategy for administrating workers' pay rates in the organizations. The cycle comprises of estimation of pay rates and assessment allowances of the workers, administrating the retirement advantages and disbursements of pay rates to representatives. It can likewise be called as a records action which embraces the compensation organization of representatives in the organization. The finance module sends bookkeeping data to the overall record for presenting ensuing on a compensation cycle. Produce checks on demand, run preliminary reports, and roll out a minute ago improvements with no issue. Adaptable highlights incorporate improved compensation preparing, Comprehensive announcing, Check printing, Direct Deposit, Tax Management, Earning and so forth Manage the progression of representative data and make changes to finance rapidly and effectively with Sage HRMS Payroll, the practical finance management arrangement. Coordinate your finance information to driving monetary bookkeeping bundles, store worker pay to a limitless number of banks, accommodate payrolls and quartercloses with regularly updated realities and moment investigation, hold the entirety of the finance exchanges for a limitless time span without having your information cleansed by your finance supplier. Finance innovation is seeing persistent movement from conventional programming to distributed computing innovation, which makes it simpler for specialist co-ops to convey their best items to end clients as cost-successfully as could reasonably 
be expected. Since distributed computing permits the entirety of the usefulness of a worker based framework with none of the upkeep and cost, it has likewise opened ways to new versatile innovation techniques, for example, finance applications for advanced cells, and creative payment strategies, for example, pay cards.

\section{Digitalization in Employee Self Service}

Employee Self Service (ESS) is a mix of innovation and authoritative change that empowers clients to interface straightforwardly with their human resource information to ask, survey and follow up on exchanges in the work environment. This human resource innovation is known as worker self assistance, manager self help, or representative direct-access frameworks. ESS guarantees a "paperless" office, smoothed out business measures, and the disposal of "authoritative" for HR staff since workers and managers direct fundamental exchanges through PC that were previously finished on paper structures and afterward handled by HR staff. There are a few sorts of self-service applications: Interactive Voice Response, Internet and intranet.

\section{Digitalization \& Workflow Management}

Work process management/Business Process Management is an arrangement of administering the way toward passing data, documents, and assignments from one representative or machine inside a business to another. Through the appropriate utilization of this framework, every one of these representatives or machines will pass the work on as per a foreordained method. As innovation propels, much work process management has gotten robotized and exploits uncommon programming to make the cycle a lot of smoother.

\section{Conclusions}

With the expanded requirement for IT in HR and an earnest need to decrease costs in organizations, one might be enticed to ponder about the chance of supplanting a couple, a few, or the entirety of the customary HR exercises through more extensive utilization of IT and mechanization. Despite the fact that this idea may be engaged by a couple, in no way, shape or form does joint effort mean replacement. There is unmistakably a critical requirement for serious coordinated effort among $\mathrm{HR}$ and IT particularly given the huge investments set independently in the process of giving birth cost and IT. Organizations in India have been attempting to change over their HR services into a variety of e-HR capacities. From one viewpoint, some of them have all their HR capacities online through the intranet and, then again, a few organizations are reforming with new work examples, for example, the virtual groups, idea of telecommuting and so forth

Thus, its expanded need apparatuses in HR, supplanted the customary techniques by the advanced strategies. Organizations are attempting to lessen their expense and time to accomplish benefit. Organizations are attempting to change over their HR Practices in to E-HR Practices. In the time of globalization, Companies need to extend worldwide by contacting the individuals the whole way across the world organizations required start to finish perceivability in their worth chain and upgraded measure effectiveness all through the organizations. There are so many organizations which are utilizing various kinds of programming's for various HR capacities, yet the serious issue is that the product's are not easy to understand, particularly the product for finance, ESS, and performance evaluation. A large portion of the organizations are reevaluating their HR innovation in view of which they host to rely upon the third get-together for the smooth working of HR movement. Another issue is the degree of mechanization isn't reliant on nature of the business; it relies on the goal of the top management. Still About $60 \%$ of the organizations have a negligible or no part of IT enablement in the zones of Policy detailing, Career and Competency management and upgrading the resolve of its workers.

The idea driving e-HR is to make an organization culture that is framework and cycle driven. The future difficulties for the organization is improve the working information on uses of e-HR among the HR expert without which e-HR can't enhance business. 
References

Amelia, Manuti, and Pasquale Palma. Digital HR: A Critical Management Approach to the Digitilization of Organizations, Palgrave Macmillan, 2018.

Baykal, Elif. Digitalization of Human Resources: $e-H R$, IGI Global, 2020.

Chytiri, Alexandra-Paraskevi. "Human Resource Managers' Role in the Digital Era." SPOUDAI Journal of Economics and Business, vol. 69, no. 1-2, 2019, pp. 62-72.

Dede, Nurten Polat. The Role of E-HRM Practices on Digital Era, IGI Global, 2020.

Ganeshan, M.K., and C. Vethirajan. "Role of the Internet in Electronic Human Resource Management (E-HRM).” EuroAsia Summit, 2020, pp. 499-506.

Girisha, M.C., and K. Nagendrababu. "Challenges and Issues of E-HRM Practices in India." Our Heritage, vol. 68, 2020, pp. 5123-5132.

Girisha, M.C., and K. Nagendrababu. "The Effect of Digitalization Perception of HR Manager and Employee in Automotive Industry." International Journal of Human Resource Management and Research, vol. 9, no. 4, 2019, pp. 113-120.

Halid, Hafinas, et al. "The Relationship between Digital Human Resource Management and Organizational Performance." Advances in Economics, Business and Management Research, 2020, pp. 96-99.
Kalita, Jumi, and Ambarish Keot. "Relationship of Digital Marketing and Human Resource Management in Modern Era." Juni Khyat, vol. 10 , no. 7,2020 , pp. 230-239.

Mangipudi, Mruthyanjaya Rao, and Rajesh Vaidya. "A Study of Digitalization in HRM and its Effectiveness in Execution of HR Strategies and Policies." HELIX, vol. 8, no. 6, 2018, pp. 4220-4222.

Mistri, Brototi, et al. "Study of E-HRM \& Digitalization." Journal of Management, vol. 1, no. 4, 2019, pp. 58-65.

Mitrofanova, E., et al. "Opportunities, Problems and Limitations of Digital Transformation of HR Management." The European Proceedings of Social \& Behavioural Sciences, 2019.

Saini, Savita. "Digital HRM and its Effective Implementation: An Empirical Study." International Journal of Management Studies, vol. 5, 2018, pp. 62-66.

Stone, Dianna L., et al. "The Influence of Technology on the Future of Human Resource Management." Human Resource Management Review, vol. 25, no. 2, 2015, pp. 216-231.

Tripathi, Roma, and Pooja Kushwaha. "A Study on Innovative Practices in Digital Human Resource Management." National Seminar on Digital Transformation of Business in India: Opportunities and Challenges, 2017.

\section{Author Details}

G. Shivaraj, Research Scholar, Department of Management Studies, Madurai Kamaraj University, Madurai, Tamil Nadu, India, Email ID: shivag8055@gmail.com 